\title{
Association and Linkage of Definite Multiple Sclerosis with HLA and the Potential Protective Role of Helicobacter Pylori Infection Among Egyptians

\section{Abstract}

Background: Multiple sclerosis (MS) is the most common chronic inflammatory demyelinating disease of the central nervous system. The linkage of multiple sclerosis to the Human Leukocyte Antigen (HLA) has been known a few decades ago. Some investigators have shown a relationship between $H$. pylori infection and Multiple sclerosis development. However, this relationship is still controversial.

Objectives: This study was designed to detect the linkage between HLA-DRB1 types and Multiple Sclerosis development, clinical presentation and course, and to try solving the controversy of the role of $H$. pylori infection in Multiple Sclerosis.

Methods: This study was carried out on 130 Egyptian individuals at the Neurology department of Mansoura University Hospital in 20122015. Group I included 80 definite relapsing remittent MS patients and Group II included 50 healthy control people. Both patients and control groups were subjected to HLA-DRB1 typing using the INNOLiPA HLA-DRB1 Plus kit. Correlation of HLA-DRB1 type to clinical presentation and course of the disease was tested. Both study groups were subjected to $\mathrm{H}$. pylori CagA and VacA IgG detection in their sera by qualitative immunoassay. All statistical analyses were performed using SPSS version 16.0.

Results: Data pooled from this study showed that number of MS cases with HLA-DRB1 * 1, 4 \&7 is statistically significantly higher than it was in the control group $(\mathrm{P}=0.01, \mathrm{P}=0.049$ and $\mathrm{P}=0.02$ respectively). The number of control individuals with HLA-DRB1 * $15 \mathrm{~g} \& 11$ types was statistically significantly higher than it was in MS patients $(P=0.003$ and $P<0.001$ ). Data also showed that the frequency of $H$. pylori antibody positive individuals is more than the negative ones in the MS patients' group but the difference was statistically insignificant $(P>0.05)$.

\author{
Azza E. Elmongui ${ }^{1}$, \\ Maha H. Khalil ${ }^{1}$, \\ Hassan H. Salama ${ }^{1}$, \\ Hamdia Askar², \\ Khaled M. Eltoukhy ${ }^{1}$
}
1 Departments of Neurology, Faculty of Medicine, Mansoura University, Egypt.
2 Medical Microbiology and Immunology, Faculty of Medicine, Mansoura University, Egypt.

Contact information:

Hamdia Askar.

झ hamdiaaskar@yahoo.co.uk 
Conclusion: Carriers of HLA-DRB1 * 1, $4 \& 7$ are at higher risk to develop MS, HLA-DRB1 * 15g \&11 exhibit a protective role against the development of Multiple Sclerosis. H. pylori infection may have a controversial causative relation to Multiple Sclerosis development.

\section{Keywords}

Multiple sclerosis; HLA-DRB1;

H. pylori.

\section{Introduction}

Multiple Sclerosis (MS) is a common demyelinating and inflammatory disease of the CNS with presumed autoimmune and multifactorial etiologies, including both environmental and multiple genetic factors [1]. The question of heterogeneity of clinical subtypes is a crucial issue in genetics of MS that could find an explanation with the association and linkage disequilibrium of different MS subtypes with distinct alleles of the human leukocyte antigen (HLA) [2].

The HLA complex is a dense cluster of genes located on the short arm of chromosome 6 at p21.3. It encompasses approximately 3,500 kilobases of DNA and contains at least 150 genes, most of which encode proteins that function in the immune system [3]. MS was one of the first diseases proven to be HLA-associated, primarily linked to HLA class II, in particular HLA-DR [4].

H. pylori that resides in the stomach of more than $50 \%$ of the entire human population are gram-negative microaerophilic bacteria [5]. H. pylori infection has a potential role in MS development in certain population. $H$. pylori infection is supposed to occur mainly before 2 years of age, primarily because the parietal cells that secrete gastric acids, which hamper the survival of $\mathrm{H}$. pylori, are not mature enough during infancy [6].

\section{Patients and Methods}

This is a prospective study carried out on 130 Egyptian individuals, in Neurology department, Mansoura University hospital from 2012 to 2015. They were divided into two groups; Group I was the patient's group which included 80 definite relapsing remittent multiple sclerosis patients chosen according to revised McDonald's criteria 2010. Group II included 50 individuals not suffering from multiple sclerosis, this represented the control group. All signed a written consent form and the study was approved by the ethical committee of the Faculty of Medicine, Mansoura University.

The individuals included in both groups were subjected to through history taking, clinical, neurological examination, radiological and clinical scaling for cognition (Montreal cognitive assessment) (MCA), quality of life (QOL scale) and Expanded Disability Status Scale (EDSS).

\section{HLA DRB1 typing}

Individuals within both groups were subjected to HLA DRB1 typing using INNO-LiPA HLA-DQB1 Update strips.

\section{Samples and procedures}

Venous blood samples ( $3 \mathrm{ml})$ were collected from all individuals included; $1 \mathrm{ml}$ was stored on EDTEA at $-80^{\circ} \mathrm{C}$ for DNA extraction using the QIAamp DNA extraction Kit (Qiagen), PCR and hybridization with DNA probes for HLA-DRB1 allele detection using the INNO-LiPA Plus kit (Innogenetics) following manufacturer's instructions. Results were interpreted using LiRASTM for LiPA HLA V6.0.11.0 (Innogenetics N.V.).

\section{Detection of H. pylori antibodies}

The rest of blood sample for each individual was incubated at $37^{\circ} \mathrm{C}$ for 30 minutes then serum was separated and stored at $-80^{\circ} \mathrm{C}$ to be used for detec- 
tion of $H$. pylori CagA and VacA-lgG using a rapid chromatographic immunoassay qualitative technique (ABON) following manufacturer's instructions.

All statistical analyses were performed using SPSS version 16.0 (SPAA Inc., Chicago, IL, USA) by using Chi square and independent sample $T$ tests.

\section{Results}

Eighty patients classified as having relapsing-remitting MS in addition to 50 control individuals were recruited into this study. The mean age \pm standard deviation of studied MS cases was $32.35 \pm 8.2$ years and the mean age \pm standard deviation of control was $28.4 \pm 5.4$ years $(P=0.004)$. There was female predominance in patients (65\%) and in controls (52\%). There was no statistically significant difference between patients and control groups regarding gender as shown in Table 1.

The number of MS patients with HLA-DRB1 * 1, 4 and 7 was statistically significantly higher than it was in the control group $(\mathrm{P}=0.01, \mathrm{P}=0.049$ and $\mathrm{P}=0.02$ respectively). However, the number of control individuals with HLA-DRB1 $* 15 \mathrm{~g}$ and 11 types was statistically significantly higher than it was in cases ( $\mathrm{P}=0.003, \mathrm{P}<0.001$ respectively) as shown in Table $\mathbf{2}$.

The frequency of $H$. pylori CagA and VacA lgGpositive individuals was higher than the negatives in both cases and controls but this difference was statistically insignificant as shown in Table $\mathbf{3}$.

There was a statistically significant linkage between HLA-sSDRB1*11 type and a higher score of QOL than found with other HLA-DRB1 types in MS cases when compared to controls $(P=0.02)$ as shown in Table 4. Patients with HLA-DR1* 13 had a statistically significant lower score of EDSS $(P=0.001)$ as shown in Table 5 . The number of cases with MCA $=30$ was statistically significantly high in the carriers of HLA-DRB1* 3, 13 and 7 ( $P=0.01, P=0.008$ and $\mathrm{P}=0.04$ respectively) as shown in Table 6 .

Among patients having 3 or more attacks, the frequency of HLA-DRB1* 14 type was statistically significantly higher than it was among patients
Table 1. Baseline characteristics of studied groups.

\begin{tabular}{|c|c|c|c|}
\hline & $\begin{array}{c}\text { MS } \\
\text { patients }\end{array}$ & $\begin{array}{l}\text { Control } \\
\text { group }\end{array}$ & \multirow{2}{*}{$\begin{array}{c}\text { Test of } \\
\text { significance }\end{array}$} \\
\hline & $\mathrm{N}=80$ & $\mathrm{~N}=50$ & \\
\hline $\begin{array}{l}\text { Age Mean士 } \\
\text { SD }\end{array}$ & $32.35 \pm 8.2$ & $28.4 \pm 5.4$ & $\begin{array}{c}p=0.004^{*} \\
t=2.9\end{array}$ \\
\hline \multicolumn{2}{|l|}{ Gender no (\%) } & & $\chi^{2}=2.16$ \\
\hline Male & $28(35)$ & $28(48)$ & $p=0.14$ \\
\hline Female & $52(65)$ & $26(52)$ & 12.75 \\
\hline
\end{tabular}

Table 2. Frequencies of HLA-DRB1 types among studied groups.

\begin{tabular}{|c|c|c|c|}
\hline & MS patients & Control group & \multirow{2}{*}{$\begin{array}{c}\text { Test of } \\
\text { significance }\end{array}$} \\
\hline & $N=80$ & $N=50$ & \\
\hline & No (\%) & No (\%) & $\mathbf{P}$ \\
\hline DRB1* 1 & $17(11.5 \%)$ & $5(5.5 \%)$ & $\star P=0.01$ \\
\hline DRB1* 3 & $23(15.5 \%)$ & $9(9.5 \%)$ & $P=0.07$ \\
\hline DRB1* 30 & $3(2.5 \%)$ & $0(0 \%)$ & $P=1$ \\
\hline $\mathrm{DRB}^{*}$ * 4 & 32 (20\%) & $14(15.5 \%)$ & $\star P=0.049$ \\
\hline $\mathrm{DRB}$ * 7 & $15(9 \%)$ & $9(9.5 \%)$ & $* P=0.02$ \\
\hline DRB1* 8 & $3(2.5 \%)$ & $1(1 \%)$ & $P=0.08$ \\
\hline DRB1* 10 & $4(2.5 \%)$ & $1(1 \%)$ & $P=0.2$ \\
\hline $\mathrm{DRB}^{*}$ * $15 \mathrm{~g}$ & $4(2.5 \%)$ & $8(8.5 \%)$ & ${ }^{*} P=0.003$ \\
\hline DRB1* 13 & $34(22 \%)$ & $24(25.5 \%)$ & $P=0.057$ \\
\hline DRB1* 11 & $6(3 \%)$ & $14(14.5 \%)$ & ${ }^{*} P<0.001$ \\
\hline DRB1* 12 & $1(1.5 \%)$ & 0 & $P=-$ \\
\hline $\mathrm{DRB}^{*}$ * $11 \mathrm{~g}$ & $7(4 \%)$ & $1(1 \%)$ & $P=0.17$ \\
\hline DRB1* 14 & $1(1.5 \%)$ & $0(0 \%)$ & $P=1$ \\
\hline DRB1* 15 & $4(2 \%)$ & $8(8.5 \%)$ & $P=0.18$ \\
\hline
\end{tabular}

Table 3. Frequencies of $H$. pylori antibodies in cases versus control group.

\begin{tabular}{|c|c|c|c|}
\hline \multirow[t]{2}{*}{ H. pylori } & $\begin{array}{c}\text { MS } \\
\text { patients }\end{array}$ & $\begin{array}{l}\text { Control } \\
\text { group }\end{array}$ & \multirow{2}{*}{$\begin{array}{c}\text { Test of } \\
\text { significance }\end{array}$} \\
\hline & $\mathrm{N}=80$ & $\mathrm{~N}=50$ & \\
\hline $32(64 \%)$ & 52 (65\%) & positive & \multirow{2}{*}{$\begin{array}{c}\chi 2=0.013 \\
p=0.9\end{array}$} \\
\hline 18 (36\%) & $28(35 \%)$ & Negative & \\
\hline
\end{tabular}


Table 4. Frequencies of HLA-DRB1 types versus QOL among studied groups.

\begin{tabular}{|c|c|c|c|c|}
\hline & \multicolumn{2}{|c|}{$\begin{array}{l}\text { MS patients (QOL) } \\
\qquad N=80\end{array}$} & \multirow[b]{2}{*}{$\begin{array}{l}\text { 96-112 } \\
\text { (pleased/ } \\
\text { delighted) }\end{array}$} & \multirow{2}{*}{$\begin{array}{l}\text { Test of } \\
\text { significance } \\
\text { (P) }\end{array}$} \\
\hline & $\begin{array}{c}<80 \\
\text { (temple/ } \\
\text { unhappy/ } \\
\text { dissatisfied) }\end{array}$ & $\begin{array}{l}\mathbf{8 0 - 9 5} \\
\text { (satisfied) }\end{array}$ & & \\
\hline DRB1*1 & 7 & 5 & 5 & 0.7 \\
\hline DRB $1 * 3$ & 13 & 6 & 4 & 0.6 \\
\hline DRB1*4 & 15 & 7 & 6 & 0.8 \\
\hline DRB1*7 & 4 & 5 & 6 & 0.12 \\
\hline DRB1*8 & 1 & 0 & 2 & 0.1 \\
\hline $\mathrm{DRB} 1 * 10$ & 3 & 1 & 0 & 0.4 \\
\hline DRB1*11 & 2 & 0 & 4 & $\star 0.02$ \\
\hline DRB1*11g & 4 & 3 & 0 & 0.2 \\
\hline DRB1*12 & 0 & 1 & 0 & 0.2 \\
\hline DRB1*13 & 13 & 11 & 7 & 0.4 \\
\hline DRB1*15 & 1 & 2 & 1 & 0.5 \\
\hline $\mathrm{DRB} 1 * 15 g$ & 2 & 1 & 1 & 0.9 \\
\hline $\mathrm{DRB} 1 * 30$ & 2 & 0 & 0 & 0.3 \\
\hline $\mathrm{DRB}{ }^{*} 14$ & 0 & 0 & 1 & 0.19 \\
\hline
\end{tabular}

Table 5. Frequencies of HLA-DRB1 types versus EDSS among studied groups.

\begin{tabular}{|c|c|c|c|}
\hline \multirow[t]{2}{*}{ HLA type } & \multicolumn{2}{|c|}{$\begin{array}{l}\text { MS patients (EDSS) } \\
\mathrm{N}=80\end{array}$} & \multirow[t]{2}{*}{$\begin{array}{l}\text { Test of significance } \\
(\mathrm{P})\end{array}$} \\
\hline & $1-4.5$ & $5-9.5$ & \\
\hline DRB1*1 & 14 & 3 & 0.5 \\
\hline DRB1*3 & 17 & 6 & 0.35 \\
\hline DRB1*4 & 20 & 8 & 0.7 \\
\hline DRB $1 * 7$ & 14 & 1 & 0.14 \\
\hline $\mathrm{DRB} 1 * 8$ & 1 & 2 & 0.09 \\
\hline $\mathrm{DRB} 1 * 10$ & 4 & 4 & 1 \\
\hline DRB1*11 & 6 & 0 & 0.15 \\
\hline $\mathrm{DRB} 1 * 12$ & 1 & 0 & 0.6 \\
\hline DRB1*13 & 30 & 1 & $0.001 *$ \\
\hline DRB1*15g & 4 & 0 & 0.2 \\
\hline DRB1*11g & 6 & 1 & 0.4 \\
\hline $\mathrm{DRB} 1 * 30$ & 2 & 0 & 0.3 \\
\hline DRB1*14 & 1 & 0 & $P=-$ \\
\hline $\mathrm{DRB} 1 * 15$ & 13 & 1 & 0.5 \\
\hline
\end{tabular}

Table 6. Frequencies of HLA-DRB1 types versus MCA among studied groups.

\begin{tabular}{|c|c|c|c|}
\hline \multirow[t]{2}{*}{ HLA } & \multicolumn{2}{|c|}{$\begin{array}{l}\text { MS patients (MCA) } \\
\qquad N=80\end{array}$} & \multirow[t]{2}{*}{$\begin{array}{c}\text { Test of significance } \\
\text { (P) }\end{array}$} \\
\hline & $<30$ & 30 & \\
\hline DRB1*1 & 9 & 8 & 0.3 \\
\hline $\mathrm{DRB}_{1}$ *3 & 11 & 12 & $\star 0.01$ \\
\hline DRB $1 * 4$ & 11 & 17 & 0.7 \\
\hline $\mathrm{DRB} 1 * 8$ & 2 & 1 & 0.2 \\
\hline $\mathrm{DRB} 1 * 10$ & 2 & 2 & 0.34 \\
\hline DRB1*11 & 0 & 6 & 0.09 \\
\hline DRB $1 * 12$ & 0 & 1 & 0.4 \\
\hline DRB1*13 & 5 & 26 & $\star 0.008$ \\
\hline DRB1*7 & 2 & 13 & *0.04 \\
\hline $\mathrm{DRB}{ }^{*} 15 \mathrm{~g}$ & 1 & 3 & 0.5 \\
\hline $\mathrm{DRB} 1 * 11 \mathrm{~g}$ & 3 & 4 & 1 \\
\hline DRB1*30 & 0 & 2 & 0.2 \\
\hline DRB1*14 & 0 & 1 & 0.5 \\
\hline DRB1*15 & 2 & 2 & 0.3 \\
\hline
\end{tabular}

Table 7. Frequencies of HLA-DRB1 types versus MCA among studied groups.

\begin{tabular}{|c|c|c|c|}
\hline \multirow[t]{2}{*}{ HLA } & \multicolumn{2}{|c|}{$\begin{array}{c}\text { MS patients } \\
\text { (No. of attacks) } \\
\mathrm{N}=80\end{array}$} & \multirow[t]{2}{*}{$\begin{array}{l}\text { Test of significance } \\
\text { (P) }\end{array}$} \\
\hline & $\leq 2$ & $\geq 3$ & \\
\hline DRB1*1 & 12 & 5 & 0.1 \\
\hline $\mathrm{DRB} 1 * 3$ & 14 & 9 & 0.7 \\
\hline $\mathrm{DRB} 1 * 4$ & 14 & 14 & 0.7 \\
\hline $\mathrm{DRB} 1 * 8$ & 1 & 2 & 0.3 \\
\hline $\mathrm{DRB} 1 * 10$ & 2 & 2 & 0.3 \\
\hline $\mathrm{DRB} 1 * 11$ & 5 & 1 & 0.2 \\
\hline $\mathrm{DRB} 1 * 12$ & 1 & 0 & 0.3 \\
\hline DRB1*13 & 23 & 8 & 0.08 \\
\hline DRB1*7 & 10 & 5 & 0.7 \\
\hline $\mathrm{DRB} 1 * 15 \mathrm{~g}$ & 3 & 1 & 0.5 \\
\hline DRB1*11g & 5 & 2 & 0.5 \\
\hline $\mathrm{DRB} 1 * 30$ & 2 & 0 & 0.2 \\
\hline $\mathrm{DRB} 1 * 14$ & 0 & 1 & $\star 0.02$ \\
\hline DRB1*15 & 3 & 1 & 0.5 \\
\hline
\end{tabular}


with 2 or less attacks $(P=0.02)$. However, cases with 2 or less attacks carried HLA-DRB1* 13 at a higher frequency when compared to those with 3 or more attacks but this was statistically insignificant as shown in Table 7.

\section{Discussion}

In this study HLA-DRB1 typing showed that HLADRB1 * 1, 4 and 7 carry a statistically significant higher risk to contribute in the development of MS. It was also shown that HLA-DRB1 * 11 and $15 \mathrm{~g}$ exhibit a statistically significant protective role against the development of MS. A study carried out on Caucasians, Europeans and North Americans proved an association of MS with the HLA-DR2 and this association has been specified to be with $\mathrm{DRBI}$ * 15 haplotype [7].

Association with HLA-DRB1*15 haplotype was then repeatedly studied in Northern European populations. Compared with Northern Europeans, African Americans are at a lower risk for MS but showed a larger haplotypic diversity regarding HLA within a case-control and family-based association studies, where a selective association with HLADRB1*15 was found [8].

However, fine-mapping studies have not settled whether the effect is explained by the DRB1 gene itself or by another closely spaced gene within the class II HLA region, such as DQB1; or by some other nearby gene in strong disequilibrium with the HLADR locus [8].

Another opinion derived from a case-control and family-based association studies of 1003 genotyped African American individuals, that showed a disease association with $\mathrm{DRB} 1 * 3$ allele $(P=0.01)$. [8]. This opinion was supported by a modest dose effect that was also detected in another study for DRB1* 3. However, in contrast to DRB1*15, this risk was recessive $(P=0.03)$. There was also a strong evidence for under-transmission of DRB $1 * 14$ $(P=5.7 \times 10-6)$ even after accounting for DRB1*15 $(P=0.03)$ was present, confirming a protective effect. In addition, a high risk DRB1*15 genotype bearing $D R B 1 * 8$ was identified $(P<0.0001)$, providing an additional evidence for trans DRB1 allelic interactions in MS [9].

A case-control study conducted in the Friuli-Venezia-Giulia region, Italy added more data. It stated that HLA-DRB1*4 was associated with a higher susceptibility to MS [10].

$H$. pylori infections has been linked to MS as it may trigger cellular and humoral immunity due to the sharing of similar epitopes present in the nervous tissue [11]. In this study, results showed that the frequency of $H$. pylori antibody positive individuals is more than the negatives in both cases and control groups but statistically insignificant, denying the possible protective role of $H$. pylori infection as regards MS and favoring a causative role.

The causative role of $H$. pylori in MS is still controversial. Several mechanisms have been proposed for how this pathogen can induce activation and proliferation of autoreactive $T$ cells. Activation of resting autoreactive $T$ cells may occur through binding a variety of $\mathrm{MHC}$ class II molecules and activation of large numbers of $\mathrm{T}$ cells, irrespective of their specificity. Pathogen-induced tissue inflammation may cause local activation of APCs and enhanced processing/presentation of self-antigens that causes $T$ cell priming, followed by $T$ cell activation and expansion of additional specificities. Another mechanism would imply that the inflammatory setting and the paracrine secretion of $T$ cell growth factors induce the expansion of activated autoreactive $T$ cells, whose small number was previously insufficient to drive the disease. Such a mechanism is referred to as bystander activation. Moreover, the H. pylori antigen can include an epitope that is structurally similar to an autoantigen epitope, causing molecular mimicry [11].

Another study of the role of $H$. pylori in the development of MS was done in southeast Iran and the prevalence of $H$. pylori CagA-specific lgG was more in patients especially in the exacerbate period. It was proposed that immune response 
against this antigen could have a critical role in MS development. This hypothesis was confirmed by the higher CagA/VacA-lgG in patients. On the other hand because of the relatively lower copy number of $H$. pylori genome and titer of $H$. pylori VacA- specific IgG in controls contrast with patients with MS exacerbation it was proposed that VacA immune response possibly has a protective role against MS [11].

On the other hand, another study was done on 105 consecutive MS patients along with 85 healthy controls, reported that $H$. pylori sero-positivity was significantly lower in patients with relapsing remittent MS patients $(p=0.018)$. These findings suggest that $H$. pylori infection is a protective factor against MS in Japanese [6].

Concerning the quality of life measures in patients with relapsing remittent MS, this study showed that there was a statistically significant linkage between HLA-DRB1*11 and higher score of QOL as compared to other HLA-DRB1 types and as regards control. There is no obvious previously reported data about linkage of HLA-DRB1 types and quality of life of MS patients.

Disability was a corner stone in assessment of patients included in this study. When the measurements of EDSS was correlated to HLA-DRB1 types it was found that patients with HLA-DR1* 13 have statistically significant lower score of EDSS. This denotes that HLA-DR1* 13 may contribute to a lower disability in MS patients.

As regards the linkage between HLA-DRB1 types and the degree of disability, there was another opinion supporting that $\mathrm{HLA}-\mathrm{DRB} 1 * 8$ allele was also associated with lower degrees of disability [12].

Another study supported that DRB1*15 increases the degree of disability in MS patients by facilitating the development of more T2-foci, thus increasing the possibility of irreversible axonal damage and subsequent neuronal degeneration leading to a decline in brain volume. These structural changes may explain the higher disability observed among
DRB1*15 patients[13]. Another study supported the same opinion [12].

The degree of cognitive decline in MS patients was correlated to HLA-DRB1 types. It was shown that the frequency of HLA-DRB1* 3, 7 and 13 types was statistically significantly higher in MS cases with MCA equals 30 than among those with MCA less than 30 denoting that these three HLA-DRB1 types have a protective role regarding cognition deterioration in MS patients.

Another study showed that DRB1*15 allele carriage increases the potential for irreversible axonal damage and neuronal degeneration causing a decrease in brain volume leading to significant decline in cognitive performance [13].

Other studies did not support the influence of HLA-DRB1 type on cognitive decline in MS patients. A research group studied the association between common HLA-DRB1 alleles and age as well as clinical disease severity descriptors: MS Severity Score, progression index and the interval between the first and second attack in 978 patients with relapsing remitting MS and secondary progressive MS. Cognition was tested using the Symbol Digit Modalities Test in 811 patients and brain atrophy was tested using the linear magnetic resonance imaging marker. The results showed that HLA-DRB1*1, 3, 4 or 15 alone or in combination did not affect cognition or cerebral atrophy [14].

The influence of HLA-DRB1 type on the rate of relapse in MS patients was one of the important findings in this study. There was a statistically significant higher frequency of HLA-DRB1* 14 allele carriage among MS cases with 3 or more attacks than among those with 2 or less attacks, denoting that this type of HLA-DRB1 exhibits a higher risk of relapse rate. Meanwhile the number of MS cases with 2 or less attacks were carrying HLA-DRB1* 13 at a higher frequency than those with 3 or more attacks but this difference was statistically insignificant denoting that this type of HLA-DRB1 may 
exhibit an influence on lowering the relapse rate in multiple sclerosis.

The influence of HLA-DRB1 on relapse rate was supported by detecting that HLA-DRB1*8 allele carriage was associated with a lower relapse rate [12].

\section{Recommendations}

1. Pooling all data from previous studies in the field of HLA typing in MS patients including this study to design a universal map for genetic susceptibility to MS in different populations.

2. Designing specific studies for linking HLADRB1* and visual evoked potential findings in MS patients as this issue was not studied thoroughly worldwide.

3. Studying the linkage between HLA-DRB1* and the clinically isolated demyelinating syndromes and the uncommon age of onset of MS (below 20 and above 40).

4. Further studies to determine the exact role of $H$. pylori infection in the development of MS.

\section{Conflict of interest}

None declared.

\section{References}

1. Sospedra, M. and R. Martin, Immunology of multiple sclerosis*. Annu. Rev. Immunol., 2005. 23: p. 683-747.

2. Sudomoina, M. and O. Favorova, A search for susceptibility genes in multiple sclerosis. Molecular Biology, 2000. 34(4): p. 561-577.

3. Dorman, J.S. and C.H. Bunker, HLA-DQ locus of the human leukocyte antigen complex and type 1 diabetes mellitus: a HUGE review. Epidemiologic reviews, 2000. 22(2): p. 218-227.

4. Miretti, M.M., E.C. Walsh, X. Ke, M. Delgado, et al., A highresolution linkage-disequilibrium map of the human major histocompatibility complex and first generation of tag singlenucleotide polymorphisms. The American Journal of Human Genetics, 2005. 76(4): p. 634-646.

5. Blaser, M.J., Helicobacter pylori: microbiology of a 'slow'bacterial infection. Trends in microbiology, 1993. 1(7): p. 255-260.

6. Li, W., M. Minohara, J.J. Su, T. Matsuoka, et al., Helicobacter pylori infection is a potential protective factor against conventional multiple sclerosis in the Japanese population. Journal of neuroimmunology, 2007. 184(1): p. 227-231.
7. Olerup, O. and J. Hillert, HLA class II-associated genetic susceptibility in multiple sclerosis: a critical evaluation. Tissue antigens, 1991. 38(2): p. 1-15.

8. Oksenberg, J.R., L.F. Barcellos, B.A. Cree, S.E. Baranzini, et al., Mapping multiple sclerosis susceptibility to the HLA-DR locus in African Americans. The American Journal of Human Genetics, 2004. 74(1): p. 160-167.

9. Barcellos, L.F., S. Sawcer, P.P. Ramsay, S.E. Baranzini, et al., Heterogeneity at the HLA-DRB1 locus and risk for multiple sclerosis. Human molecular genetics, 2006. 15(18): p. 28132824.

10. Zivadinov, R., L. Uxa, A. Bratina, A. Bosco, et al., HLA-DRB1* 1501,-DQB1* 0301, -DQB1*0302, $-D Q B 1 * 0602$, and-DQB1* 0603 Alleles are Associated With More Severe Disease Outcome on Mri in Patients With Multiple Sclerosis. International review of neurobiology, 2007. 79: p. 521-535.

11. Sanadgol, N., E. Shahraki, and J. Estakhr, Relationship between Helicobacter Pylori (H. pylori) Infection and Multiple Sclerosis (MS) in Southeast of Iran. Current Research Journal of Biological Sciences, 2012. 4(4): p. 422-426.

12. Balnyte, R., D. Rastenyte, A. Vaitkus, D. Mickeviciene, et al., The importance of HLA DRB1 gene allele to clinical features and disability in patients with multiple sclerosis in Lithuania. BMC neurology, 2013. 13(1): p. 77.

13. Okuda, D., R. Srinivasan, J. Oksenberg, D. Goodin, et al., Genotype-phenotype correlations in multiple sclerosis: HLA genes influence disease severity inferred by $1 H M R$ spectroscopy and MRI measures. Brain, 2009. 132(1): p. 250-259.

14. Van der Walt, A., J. Stankovich, M. Bahlo, B.V. Taylor, et al., Heterogeneity at the HLA-DRB1 allelic variation locus does not influence multiple sclerosis disease severity, brain atrophy or cognition. Multiple Sclerosis Journal, 2011. 17(3): p. 344-352.

\section{Publish in International Archives of Medicine}

International Archives of Medicine is an open access journal publishing articles encompassing all aspects of medical science and clinical practice. IAM is considered a megajournal with independent sections on all areas of medicine. IAM is a really international journal with authors and board members from all around the world. The journal is widely indexed and classified Q1 in category Medicine. 